\title{
Protective effects of scoparone against ischemia-reperfusion-induced myocardial injury
}

\author{
CHUNFU WAN $^{1}$, YUEYUE WEI ${ }^{2}$, JIANGUO MA ${ }^{2}$ and XIAOYONG GENG ${ }^{3}$ \\ ${ }^{1}$ Department of Pain and Rehabilitation, Fourth Hospital of Hebei Medical University; \\ Departments of ${ }^{2}$ Urology and ${ }^{3}$ Cardiology, The Third Hospital of Hebei Medical University, \\ Shijiazhuang, Hebei 050051, P.R. China
}

Received January 9, 2017; Accepted February 9, 2018

DOI: $10.3892 / \mathrm{mmr} .2018 .9123$

\begin{abstract}
The present study aimed to investigate the protective effects and molecular mechanisms of scoparone on ischemia-reperfusion (I/R) injury in primary cultured cardiac myocytes and rats. An in vivo rat model of $I / R$ injury and an in vitro primary cultured cardiac myocyte model of oxygen-glucose deprivation/reoxygenation were used to investigate the protective effects of scoparone. Cell viability, lactate dehydrogenase (LDH) release, superoxide dismutase (SOD), creatine kinase (CK) and malondialdehyde (MDA) levels, and reactive oxygen species (ROS) production were subsequently measured. In addition, cell apoptosis was assessed by terminal deoxynucleotidyl-transferase-mediated dUTP nick end labeling staining, and myocardial infarct area (IA) was determined by triphenyl tetrazolium chloride staining. Furthermore, the protein expression levels of B-cell lymphoma 2 (Bcl-2), Bcl-2-associated X protein (Bax), cytochrome $c$ (Cyt C) and caspase-3 were assessed by western blotting. The results demonstrated that treatment with scoparone markedly increased cell viability, SOD levels and Bcl-2 protein expression, and decreased LDH release, MDA production, CK levels, ROS concentration, cell apoptotic rate, myocardial IA, and Bax, caspase-3 and Cyt $\mathrm{C}$ protein expression. These findings indicated that scoparone may have a protective effect against $\mathrm{I} / \mathrm{R}$ injury, thus suggesting that scoparone may be a considered a potential drug for the treatment of I/R injury via the inhibition of oxidative stress and cell apoptosis.
\end{abstract}

\section{Introduction}

Scoparone is obtained from Artemisiae Scopariae Herba, which is a traditional Chinese medicine. Artemisiae Scopariae

Correspondence to: $\mathrm{Dr}$ Xiaoyong Geng, Department of Cardiology, The Third Hospital of Hebei Medical University, 139 Ziqiang Road, Shijiazhuang, Hebei 050051, P.R. China

E-mail: hbsjzgxy@icloud.com

Key words: cardioprotective, scoparone, ischemia-reperfusion injury, cell apoptosis
Herba refers to the aerial parts of Artemisia capillaris Thunb. or Artemisia Scoparia Waldst. et Kit., which are mainly distributed in China, Japan, Korea and Mongolia (1). Artemisiae Scopariae Herba has numerous effects, and has been reported to possess anti-inflammatory, antioxidant, antiviral and antitumor activities. In addition, it regulates immunity, blood sugar, blood lipid levels and blood pressure (1). Previous experimental and clinical studies have reported that Artemisiae Scopariae Herba exerts therapeutic effects against hepatobiliary disease, postoperative sequelae of gynecological diseases, maternal-fetal blood group incompatibility, severe acute pancreatitis, pneumonia, diabetes, oral ulcers, acute conjunctivitis and cancer (2-7).

Scoparone, which is also known as 6,7-dimethoxycoumarin, is a potent anti-inflammatory agent that has been reported to exert anti-inflammatory effects via inhibition of the transcriptional activity of nuclear factor- $\kappa \mathrm{B}$ (8). Scoparone has previously been reported to inhibit interleukin (IL)-8 and monocyte chemoattractant protein 1 production in U937 cells, and tumor necrosis factor- $\alpha$, IL- 6 and IL- $1 \beta$ production in lipopolysaccharide-stimulated RAW264.7 cells (9). Scoparone also possesses antitumor activity in DU145 androgen-independent prostate cancer cells via the inhibition of signal transducer and activator of transcription 3 activity (10). Furthermore, scoparone may enhance bilirubin clearance in the liver by activating constitutive androstane receptor, which is a nuclear receptor that acts as a transcription factor to upregulate the expression of bilirubin glucuronyl transferase and other components of the bilirubin metabolism pathway (11). In addition, scoparone exerts protective effects against alterations in plasma lipoproteins, vascular morphology and vascular reactivity in hyperlipidaemic diabetic rabbits, which may be partly due to its free radical scavenging abilities (12). However, to the best of our knowledge, there are currently no studies regarding the protective effects of scoparone against ischemia-reperfusion (I/R)-induced cardiac myocyte injury, and the associated mechanisms have not been reported. The present study aimed to investigate the protective effects and molecular mechanisms of scoparone on I/R-induced myocardial injury in an in vitro primary cultured cardiac myocyte model of oxygen-glucose deprivation/reoxygenation (OGD/R) and an in vivo rat model of $\mathrm{I} / \mathrm{R}$. 


\section{Materials and methods}

Reagents. Scoparone was purchased from Dalian Meilun Biology Technology Co., Ltd., (Dalian, China).

Primary cultures of neonatal rat cardiac myocytes. Cardiac myocytes were prepared from 20 neonatal Sprague-Dawley rats (Male, 1-3 days-old, $10 \mathrm{~g}$ ) as previously described (13). Rats were obtained from Hebei Medical University. Rats were housed under the same standard environmental conditions of light (a 12-h light/dark cycle), temperature $\left(22 \pm 2^{\circ} \mathrm{C}\right)$, and ambient humidity of $50 \pm 10 \%$ with free access to food and water. Briefly, the obtained ventricles were cut into sections, which were digested with trypsin at $37^{\circ} \mathrm{C}$ for $8 \mathrm{~min}$. Subsequently, the supernatant was added to Dulbecco's modified Eagle's medium (DMEM; Hyclone; GE Healthcare Life Sciences, Logan, UT, USA) containing 10\% fetal bovine serum (FBS, Gibco; Thermo Fisher Scientific, Inc., Waltham, MA, USA). The digestion step was repeated 6-8 times, until the tissue sections were digested. Cell suspensions were centrifuged at $800 \mathrm{x} \mathrm{g}$ for $5 \mathrm{~min}$ at $37^{\circ} \mathrm{C}$, and the cells were cultured with DMEM containing $10 \% \mathrm{FBS}$ at $37^{\circ} \mathrm{C}$ in an atmosphere containing $5 \% \mathrm{CO}_{2}$ for $2 \mathrm{~h}$. The non-adherent cell suspension was collected to separate fibroblast cells and cardiac myocytes based on the varying durations of adherence. The fibroblast cells and cardiac myocytes were separated by its adherent at different time. The cardiac myocytes $\left(1 \times 10^{5} \mathrm{cells} / \mathrm{ml}\right)$ were cultured in DMEM containing $10 \% \mathrm{FBS}, 100 \mathrm{U} / \mathrm{ml}$ penicillin, $100 \mathrm{mg} / \mathrm{ml}$ streptomycin and $2 \mathrm{~g} / \mathrm{ml}$ vitamin B12. After $48 \mathrm{~h}$, dead cells were removed, and the medium was replaced with fresh medium containing $0.1 \mathrm{mM}$ bromodeoxyuridine. The cardiac myocytes were assessed by immunofluorescence staining with $\alpha$-actin (cat. no. sc-58670; Santa Cruz Biotechnology, Inc., Dallas, Texas, USA) as previously described (13); myocardial cell purity was confirmed at $>95 \%$.

$O G D / R$ model. OGD/R was performed on primary cultured neonatal rat cardiac myocytes according to previously described methods (14). Briefly, primary cultured neonatal rat cardiac myocytes were randomly divided into five groups: Control group, OGD/R group, scoparone low-dose group (S-L), scoparone mid-dose group (S-M) and scoparone high-dose group (S-H). The control group was incubated without any treatment. As for the OGD/R group, the cell medium was replaced with DMEM (glucose-free), which was preincubated with a mixture of $5 \% \mathrm{CO}_{2}$ and $95 \% \mathrm{~N}_{2}$ for $20 \mathrm{~min}$ to remove $\mathrm{O}_{2}$. Subsequently, cells were cultured in an incubator containing $5 \% \mathrm{CO}_{2}$ and $95 \% \mathrm{~N}_{2}$ at $37^{\circ} \mathrm{C}$. After $3 \mathrm{~h}$, the medium was replaced with DMEM containing glucose, and cardiac myocytes were transferred into an incubator containing 5\% $\mathrm{CO}_{2}$ at $37^{\circ} \mathrm{C}$ for $1 \mathrm{~h}$. The cells in the S-L, S-M and S-H groups were pretreated with scoparone at 100,500 and $1,000 \mathrm{mg} / \mathrm{ml}$, respectively, for $1 \mathrm{~h}$ prior to $\mathrm{OGD} / \mathrm{R}$, which was conducted as described for the OGD/R group.

$I / R$ rat model. Male Wistar rats with body weight ranging from 240-260 g, 7-weeks old were used in the present study. Rats were obtained from Hebei Medical University and were housed under the same standard environmental conditions of light (12-h light/dark cycle), temperature $\left(22 \pm 2^{\circ} \mathrm{C}\right)$, and ambient humidity of $50 \pm 10 \%$ with free access to food and water. A total of 120 Wistar rats were randomly divided into five groups: Sham-operated group (sham), I/R group, scoparone low-dose group (S-L), scoparone mid-dose group (S-M) and scoparone high-dose group ( $\mathrm{S}-\mathrm{H})(\mathrm{n}=24$ rats/group). Briefly, the rats were anesthetized with ether and an incision was made in the chest to expose the heart. The left anterior descending branch of the coronary artery was then isolated. With the exception of the sham group, in the other groups, the coronary artery was immediately ligated with line 0 (15); the groups underwent ischemia for $30 \mathrm{~min}$, followed by $120 \mathrm{~min}$ of reperfusion. Scoparone was administered $1 \mathrm{~h}$ prior to ligation. The rats in the sham and I/R groups were intravenously injected with $2 \mathrm{ml} / \mathrm{kg}$ normal saline, whereas the rats in the S-L, S-M and S-H groups were intravenously injected with $25,50,100 \mathrm{mg} / \mathrm{kg}$ scoparone, respectively. The rats were sacrificed after reperfusion and myocardial tissues were collected. The present study was approved by the Ethics Committee of Hebei Medical University (Shijiazhaung, China).

Cell viability assay. Following OGD/R in vitro, cell viability was determined using MTT reagent. Cells $\left(1 \times 10^{5} / \mathrm{ml}\right)$ were cultured with MTT reagent (final concentration, $0.5 \mathrm{mg} / \mathrm{ml}$ ) for $4 \mathrm{~h}$ at $37^{\circ} \mathrm{C}$. The medium was then removed and dimethyl sulfoxide $(150 \mu \mathrm{l})$ was added to each well for $15 \mathrm{~min}$ at $37^{\circ} \mathrm{C}$, in order to solubilize formazan. The absorbance of formazan was measured at $492 \mathrm{~nm}$, which is directly proportional to cell viability.

Cell apoptosis assay. The apoptotic rates of cardiac myocytes subjected to OGD/R injury in vitro and I/R injury in vivo were measured by terminal deoxynucleotidyl-transferase-mediated dUTP nick end labeling (TUNEL) assay using a TUNEL kit (In situ Cell Death Detection kit, fluorescein; Roche Diagnostics, Indianapolis, IN, USA) according to manufacturer's protocols. The cell nucleus was stained with DAPI (Roche Diagnostics) according to manufacturer's protocols. Positive TUNEL staining was observed under a fluorescence microscope (TE2000U; Nikon Corporation, Tokyo, Japan) using a B-2A filter (450-490 $\mathrm{nm}$ excitation filter, $505 \mathrm{~nm}$ dichroic mirror, $520 \mathrm{~nm}$ bandpass filter). The ratio was determined by calculating the number of TUNEL-positive cells to the total number of cells in each of the 10 fields of view.

ELISA assay. Following OGD/R in vitro, cell culture medium was collected. The levels of lactate dehydrogenase (LDH) and creatine kinase (CK) were measured using commercial ELISA kits (cat. nos. JL13677 and 0-025486; Shanghai Jiang Lai Biological Technology Co., Ltd., Shanghai, China), according to the manufacturer's protocols. In addition, the cells were collected by centrifugation $\left(1,000 \mathrm{xg}, 5 \mathrm{~min}, 37^{\circ} \mathrm{C}\right)$, and the levels of malondialdehyde (MDA) and superoxide dismutase (SOD) were measured using commercial ELISA kits (cat. no. JL13297 and JL11065; Shanghai Jiang Lai Biological Technology Co., Ltd.) according to the protocols recommended by the manufacturer.

Following I/R in vivo, serum samples were collected by centrifugation $\left(3,000 \mathrm{x} \mathrm{g}, 10 \mathrm{~min}, 4^{\circ} \mathrm{C}\right)$ from myocardial tissues. The concentrations of $\mathrm{LDH}$ and $\mathrm{CK}$ in the serum were detected using ELISA kits (cat. nos. JL13677 and 0-025486; Shanghai Jiang Lai Biological Technology Co., Ltd.) according 
to manufacturer's protocols. In addition, myocardial tissues were collected from all rats to detect MDA and SOD levels. Ice physiological saline is added to the myocardial tissues. A total of $10 \%$ myocardial tissue homogenate was made by using a high-speed homogenizer and centrifuged $3,000 \mathrm{x}$ g at $4^{\circ} \mathrm{C}$. The supernatant was collected. The levels of MDA and SOD in the supernatant were determined using commercial kits (cat. nos. JL13297 and JL11065; Shanghai Jiang Lai Biological Technology Co.,Ltd.) according to the manufacturer's protocols.

Reactive oxygen species (ROS) assay. Intracellular ROS levels were measured using a fluorescent carboxy- $\mathrm{H}_{2}$ DCFDA probe, as previously described (16). Carboxy- $\mathrm{H}_{2} \mathrm{DCFDA}$ is hydrolyzed to $\mathrm{H}_{2} \mathrm{DCF}$ in cells; $\mathrm{H}_{2} \mathrm{DCF}$ emits no fluorescence and cannot leave the cell through the cell membrane. However, ROS can oxidize $\mathrm{H}_{2} \mathrm{DCF}$ to DCF, which emits a green fluorescence; therefore, detection of the fluorescence intensity of DCF can reflect intracellular ROS levels; the fluorescence intensity is proportional to the concentration of ROS. Following I/R injury, the myocardium was homogenized in Hank's buffered salt solution and the supernatant was collected. The samples were cultured with $10 \mu \mathrm{M}$ carboxy- $\mathrm{H}_{2}$ DCFDA for $20 \mathrm{~min}$ at $37^{\circ} \mathrm{C}$ in the dark. The fluorescence signal intensity of DCF was detected using a flow cytometer with $488 \mathrm{~nm}$ excitation wavelength and $600 \mathrm{~nm}$ detection wavelength. Expo $32 \mathrm{ADC}$ (Beckman Coulter, Inc., Brea, CA, USA) was used to analyze the fluorescence data.

Measurement of infarct area (IA). Myocardial IA was determined using the triphenyl tetrazolium chloride (TTC) staining method (17). Briefly, the heart samples were frozen and sliced into $1 \mathrm{~mm}$ sections along the vertical axis. The sections were incubated for $15 \mathrm{~min}$ at $37^{\circ} \mathrm{C}$ in $1 \% \mathrm{TTC}$, and were then immersed in $4 \%$ formaldehyde for $12 \mathrm{~h}$ at $37^{\circ} \mathrm{C}$. IA were determined using Image-Pro Plus 6.0 (Media Cybernetics, Inc., Rockville, MD, USA).

Western blotting. Following OGD/R in vitro, cardiac myocytes were collected and lysed at $4^{\circ} \mathrm{C}$ with lysis buffer (Tiangen Biotech, Co., Ltd., Beijing, China) containing $1 \mu \mathrm{M}$ phenylmethylsulfonyl fluoride. Protein concentration was determined according to the bicinchoninic acid method. Equal amounts of protein $(100 \mu \mathrm{g})$ were separated by $10 \%$ SDS-PAGE and were electrotransferred onto a polyvinylidene fluoride membrane. The membrane was blocked with Tris-buffered saline (TBS) containing $5 \%$ skimmed milk for $1 \mathrm{~h}$ at $37^{\circ} \mathrm{C}$, and was then incubated with primary antibodies against B-cell lymphoma 2 (Bcl-2; cat. no. ab692), Bcl-2-associated X protein (Bax; cat. no. ab77566), caspase-3 (cat. no. ab13585) and cytochrome $c$ (Cyt C; cat. no. ab110325; Abcam, Cambridge, MA USA), all 1:100 dilution, at $4^{\circ} \mathrm{C}$ overnight. Subsequently, the membrane was washed with TBST [TBS, $(\mathrm{pH} 7.5)$ containing $0.1 \%$ Tween-20] and was incubated with an anti-Mouse immunoglobulin $\mathrm{G}(\operatorname{IgG}) \mathrm{H} \& \mathrm{~L}$ secondary antibody (1:10,000; cat. no. ab6785; Abcam) for $1 \mathrm{~h}$ at $37^{\circ} \mathrm{C}$. Signals were then developed using the Enhanced Chemiluminescence Plus Western Blotting Detection system (Amersham; GE Healthcare Life Sciences, Little Chalfont, UK). Signal intensities were semi-quantified by densitometry using Image J v1.45 software (National Institutes of Health, Bethesda, MD,

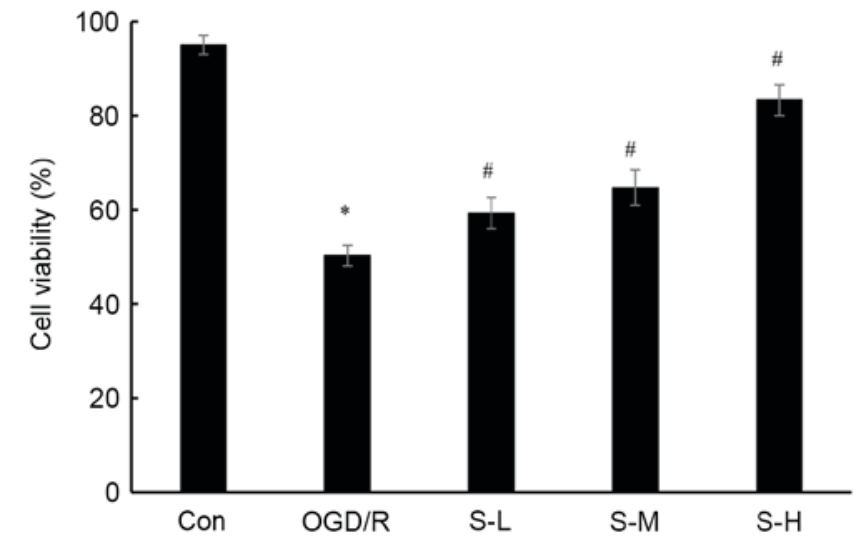

Figure 1. Effects of scoparone on viability of cardiac myocytes following $\mathrm{OGD} / \mathrm{R}$ injury. Con group, cells were cultured under normal conditions; $\mathrm{OGD} / \mathrm{R}$ group, cells were subjected to $3 \mathrm{~h}$ OGD and $1 \mathrm{~h}$ recovery; S-L, S-M and S-H groups, cells were pretreated with scoparone at concentrations of 100,500 and $1,000 \mathrm{mg} / \mathrm{ml}$, respectively, for $1 \mathrm{~h}$ prior to OGD/R. Data are presented as the means \pm standard deviation of three independent experiments. ${ }^{*} \mathrm{P}<0.05$ vs. the Con group; ${ }^{\#} \mathrm{P}<0.05$ vs. the OGD/R group. Con, control; OGD/R, oxygen-glucose deprivation/reoxygenation; S-H, scoparone high-dose; S-L, scoparone low-dose; S-M, scoparone mid-dose.

USA) and were normalized against the corresponding $\beta$-actin (cat. no. ab8226; Abcam) signals. The antibody was diluted by 1:1,000 and incubated for $1 \mathrm{~h}$ at $37^{\circ} \mathrm{C}$.

Immunohistochemical staining. Harvested myocardial tissues were fixed in formalin overnight at $37^{\circ} \mathrm{C}$, paraffin embedded; serial sections (3-5 $\mu \mathrm{m})$ obtained. The myocardial sections were blocked with $3 \%$ hydrogen peroxide for $15 \mathrm{~min}$ at room temperature. Subsequently, the sections were microwaved in $10 \mathrm{mmol} / \mathrm{l}$ (pH 8.0) EDTA (Sangon Biotech Co., Ltd., Shanghai, China) for 2 min, incubated with 5\% goat serum (Shanghai Haoran Bio, Shanghai, China) for $1 \mathrm{~h}$ at $37^{\circ} \mathrm{C}$, and incubated overnight at $4^{\circ} \mathrm{C}$ with various antibodies (Cyt c, caspase- $3, \mathrm{Bcl}-2$ and Bax) as aforementioned. Anti-Mouse IgG H\&L was used as aforementioned. To analyze staining, the following systems were used: PicTure PV6000 and Elivision Plus (Fuzhou Maixin Biotech Development Co., Ltd., Fuzhou, China). Finally, the sections were counterstained with hematoxylin $\left(3 \mathrm{~min}, 37^{\circ} \mathrm{C}\right)$. An Olympus BX41 brightfield microscope (Olympus Corporation, Tokyo, Japan) was used to observe sections.

Statistical analysis. Data are presented as the means \pm standard deviation. Experiments were repeated in triplicate. All data were analyzed using one-way analysis of variance followed by Bonferroni post hoc test (SPSS software package version 19.0; SPSS, Inc., Chicago, IL, USA). P $<0.05$ was considered to indicate a statistically significant difference.

\section{Results}

Protective effects of scoparone on $O G D / R$ injury in cardiac myocytes. Following OGD/R injury in cardiac myocytes, cell viability and SOD activity were significantly reduced, whereas LDH release, MDA levels, CK activity and cell apoptosis were markedly increased. Scoparone, at concentrations of 100, 500 and $1,000 \mathrm{mg} / \mathrm{ml}$, attenuated these alterations in a dose-dependent manner (Figs. 1-3). In cardiac myocytes treated with 100, 

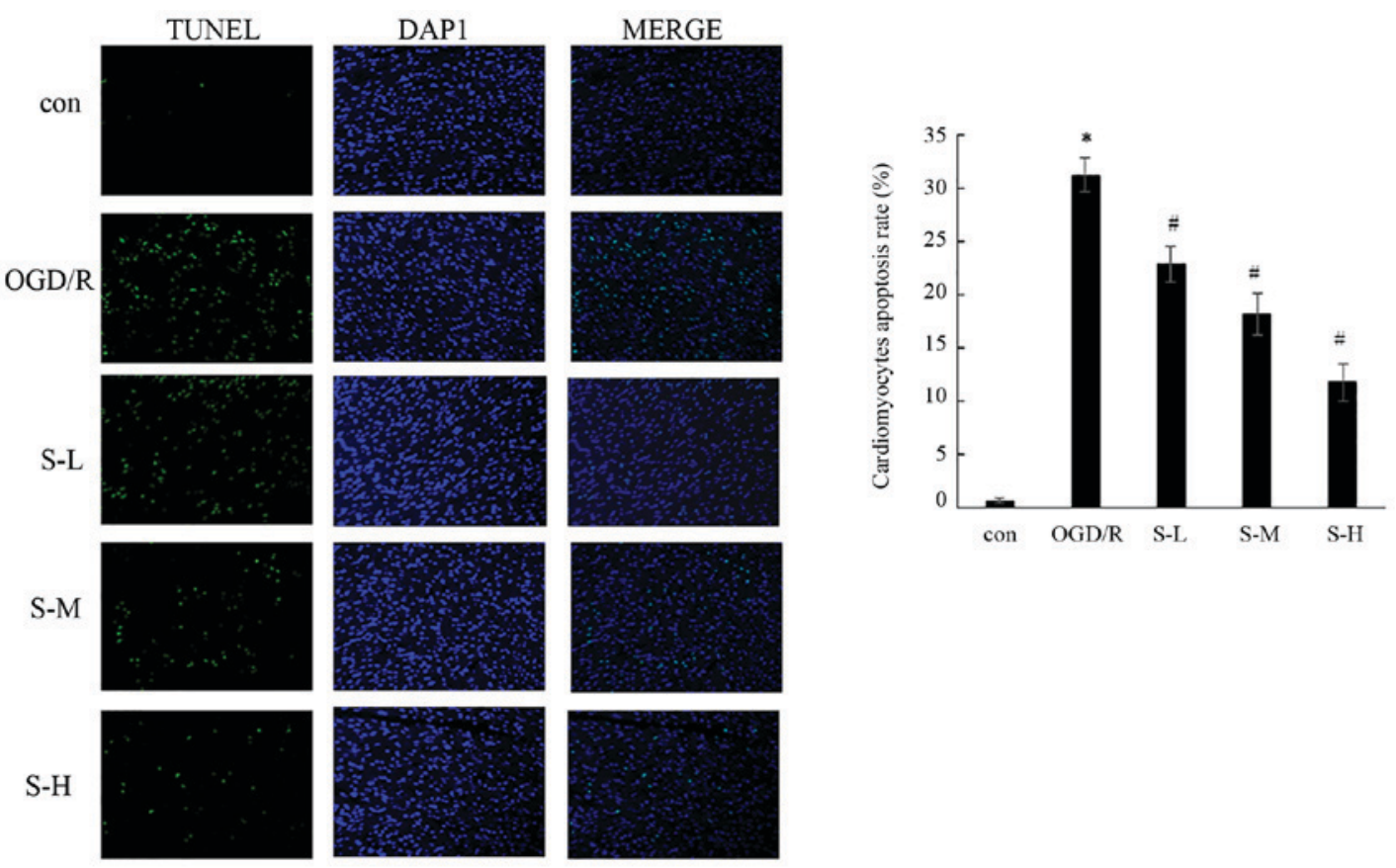

Figure 2. Effects of scoparone on cell apoptosis in cardiac myocytes following OGD/R injury. Con group, cells were cultured under normal conditions; OGD/R group, cells were subjected to $3 \mathrm{~h}$ OGD and $1 \mathrm{~h}$ recovery; S-L, S-M and S-H groups, cells were pretreated with scoparone at concentrations of 100,500 and $1,000 \mathrm{mg} / \mathrm{ml}$, respectively, for $1 \mathrm{~h}$ prior to OGD/R. Data are presented as the means \pm standard deviation of three independent experiments. ${ }^{*} \mathrm{P}<0.05 \mathrm{vs}$. the Con group; ${ }^{\#} \mathrm{P}<0.05$ vs. the OGD/R group. Con, control; OGD/R, oxygen-glucose deprivation/reoxygenation; $\mathrm{S}-\mathrm{H}$, scoparone high-dose; $\mathrm{S}-\mathrm{L}$, scoparone low-dose; S-M, scoparone mid-dose; TUNEL, terminal deoxynucleotidyl-transferase-mediated dUTP nick end labeling.

500 and $1,000 \mathrm{mg} / \mathrm{ml}$ scoparone prior to OGD/R injury, cell viability was increased by $17.9,28.7$ and $65.7 \%$, respectively; cell apoptosis was decreased by $27.0,41.7$ and $62.2 \%$, respectively; LDH levels were decreased by $12.8,32.1$ and $52.8 \%$, respectively; MDA production was decreased by $13.7,28.6$ and $47.4 \%$, respectively; SOD activity was increased by 24.4 , 56 and $82.4 \%$, respectively; and CK activity was decreased by $24.2,47.2$ and $62.7 \%$, respectively.

Protective effects of scoparone on $I / R$ injury in rats. Following I/R injury in rats, the levels of LDH and MDA, and SOD and CK activities were detected. I/R significantly increased the LDH levels $(4,152.51 \pm 487.31 \mathrm{U} / \mathrm{l})$, MDA production $(10.547 \pm 0.92 \mathrm{mmol} / \mathrm{ml})$, and CK activity $(1,137.18 \pm 106.35 \mathrm{U} / \mathrm{ml})$, whereas SOD activity was significantly decreased $(1,684.68 \pm 143.56 \mathrm{U} / \mathrm{l})$ compared with in the sham group (Fig. 4; $\mathrm{P}<0.05$ ). Conversely, compared with the $\mathrm{I} / \mathrm{R}$ group, scoparone was revealed to significantly decrease the LDH levels $(4,034.15 \pm 428.23$, $3,502.53 \pm 412.04 \mathrm{U} / 1$ and $3,425.14 \pm 482.47 \mathrm{U} / 1$, respectively; $\mathrm{P}<0.05)$, MDA production $(8.677 \pm 0.495,7.621 \pm 0.587$ and $6.805 \pm 0.647 \mathrm{mmol} / \mathrm{ml}$, respectively; $\mathrm{P}<0.05$ ), and CK activity $(924.478 \pm 38.841,766.758 \pm 43.812$ and $708.158 \pm 83.958 \mathrm{U} / 1$, respectively; $\mathrm{P}<0.05)$, whereas SOD activity was increased $(1,977.341 \pm 176.902,2,173.923 \pm 185.483$ and $2,365.837 \pm 166.384 \mathrm{U} / 1$, respectively; $\mathrm{P}<0.05)$ in a dose-dependent manner, compared with the I/R group (Fig. 4).

Effects of scoparone on I/R injury-induced cardiac myocyte apoptosis in rats. The apoptotic rate of cardiac myocytes was detected by TUNEL staining. The results indicated that the percentage of apoptotic cardiac myocytes was significantly increased in the $\mathrm{I} / \mathrm{R}$ group $(34.95 \pm 1.53 \%)$, compared with in the sham group (Fig. 5 ; $\mathrm{P}<0.05$ ). Treatment with scoparone, at doses of 25,50 and $100 \mathrm{mg} / \mathrm{kg}$, resulted in a dose-dependent reduction in the apoptotic rate of cardiac myocytes following I/R injury, to $26.14 \pm 1.71,22.11 \pm 1.98$ and $12.13 \pm 1.54 \%$, respectively.

Effects of scoparone on I/R injury-induced myocardial IA in rats. TTC staining was conducted to determine the effects of scoparone on myocardial infarct size in I/R rats (Fig. 6). In the I/R group, myocardial IA was $85.09 \pm 2.53 \%$, which was a significantly increased compared with the sham group $(\mathrm{P}<0.05)$. Treatment of scoparone, at a dose of 25,50 and $100 \mathrm{mg} / \mathrm{kg}$, significantly reduced myocardial IA $(43.98 \pm 1.96$, $25.64 \pm 2.36$ and $9.05 \pm 1.87 \%$, respectively) compared with in the $\mathrm{I} / \mathrm{R}$ group $(\mathrm{P}<0.05)$.

Effects of scoparone on ROS concentration in rats following $I / R$ injury. ROS concentration was determined following I/R using a carboxy- $\mathrm{H}_{2}$ DCFDA probe. The fluorescence intensity of DCF represents the concentration of ROS. As shown in Fig. 7, I/R injury significantly increased fluorescence intensity compared with in the sham group $(677.93 \pm 37.44 \%$ of control). However, scoparone pretreatment, at a dose of 25,50 and $100 \mathrm{mg} / \mathrm{kg}$, significantly decreased fluorescence intensity $(454.29 \pm 32.32,346.64 \pm 30.90,224.45 \pm 27.44 \%$ of control, respectively) induced by $\mathrm{I} / \mathrm{R}$ in a dose-dependent manner.

Effects of scoparone on caspase-3 and Cyt $C$ expression. As shown in Fig. 8, the results of western blot analysis indicated that caspase- 3 and $\mathrm{Cyt} C$ expression were increased following OGD/R injury. Conversely, scoparone, at concentrations of 

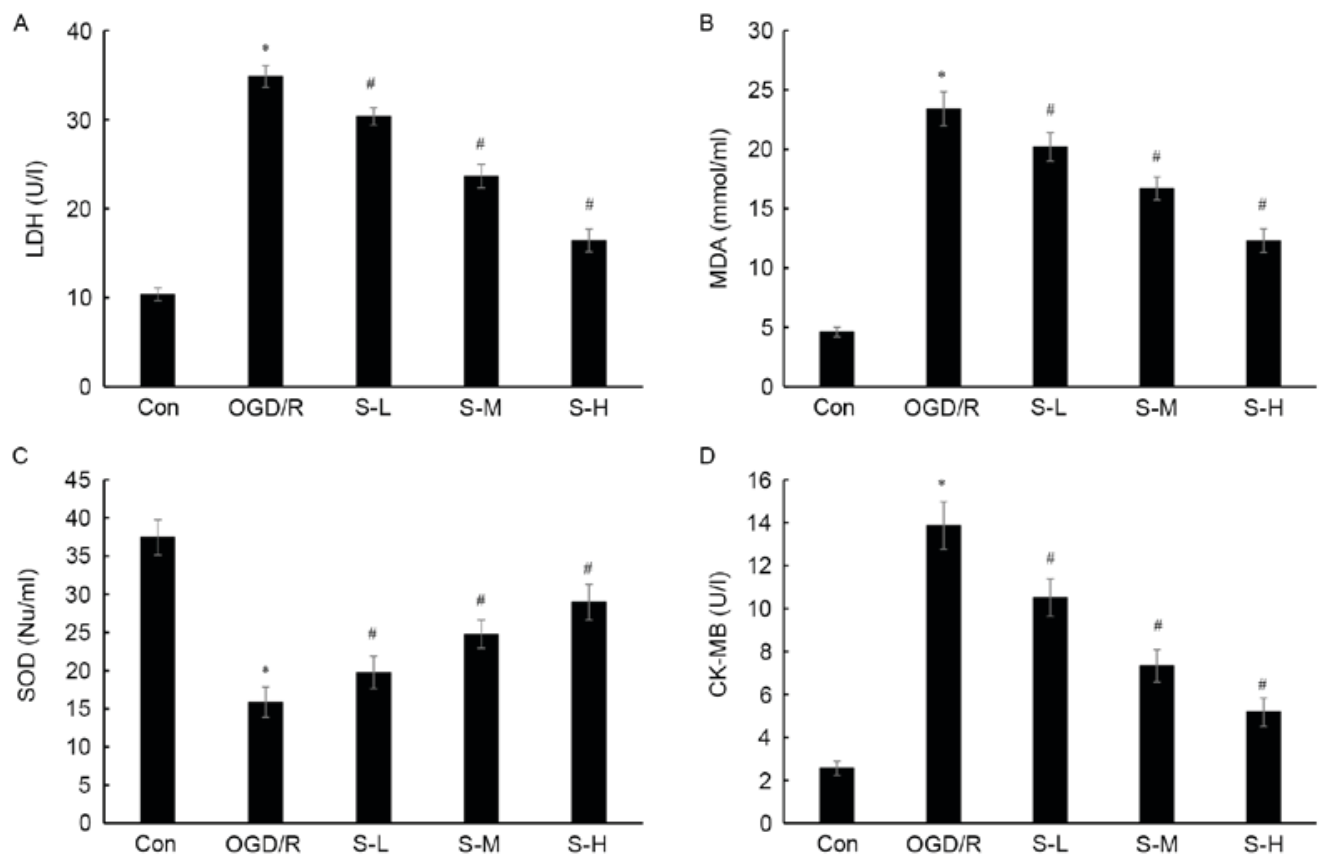

Figure 3. Effects of scoparone on (A) LDH, (B) MDA, (C) SOD and (D) CK levels in cardiac myocytes following OGD/R injury. Con group, cells were cultured under normal conditions; OGD/R group, cells were subjected to $3 \mathrm{~h}$ OGD and $1 \mathrm{~h}$ recovery; S-L, S-M and S-H groups, cells were pretreated with scoparone at concentrations of 100,500 and $1,000 \mathrm{mg} / \mathrm{ml}$, respectively, for $1 \mathrm{~h}$ prior to OGD/R. Data are presented as the means \pm standard deviation of three independent experiments. " $\mathrm{P}<0.05$ vs. the Con group; ${ }^{*} \mathrm{P}<0.05$ vs. the $\mathrm{OGD} / \mathrm{R}$ group. $\mathrm{CK}$, creatine kinase; Con, control; $\mathrm{LDH}$, lactate dehydrogenase; MDA, malondialdehyde; OGD/R, oxygen-glucose deprivation/reoxygenation; S-H, scoparone high-dose; S-L, scoparone low-dose; S-M, scoparone mid-dose; SOD, superoxide dismutase.
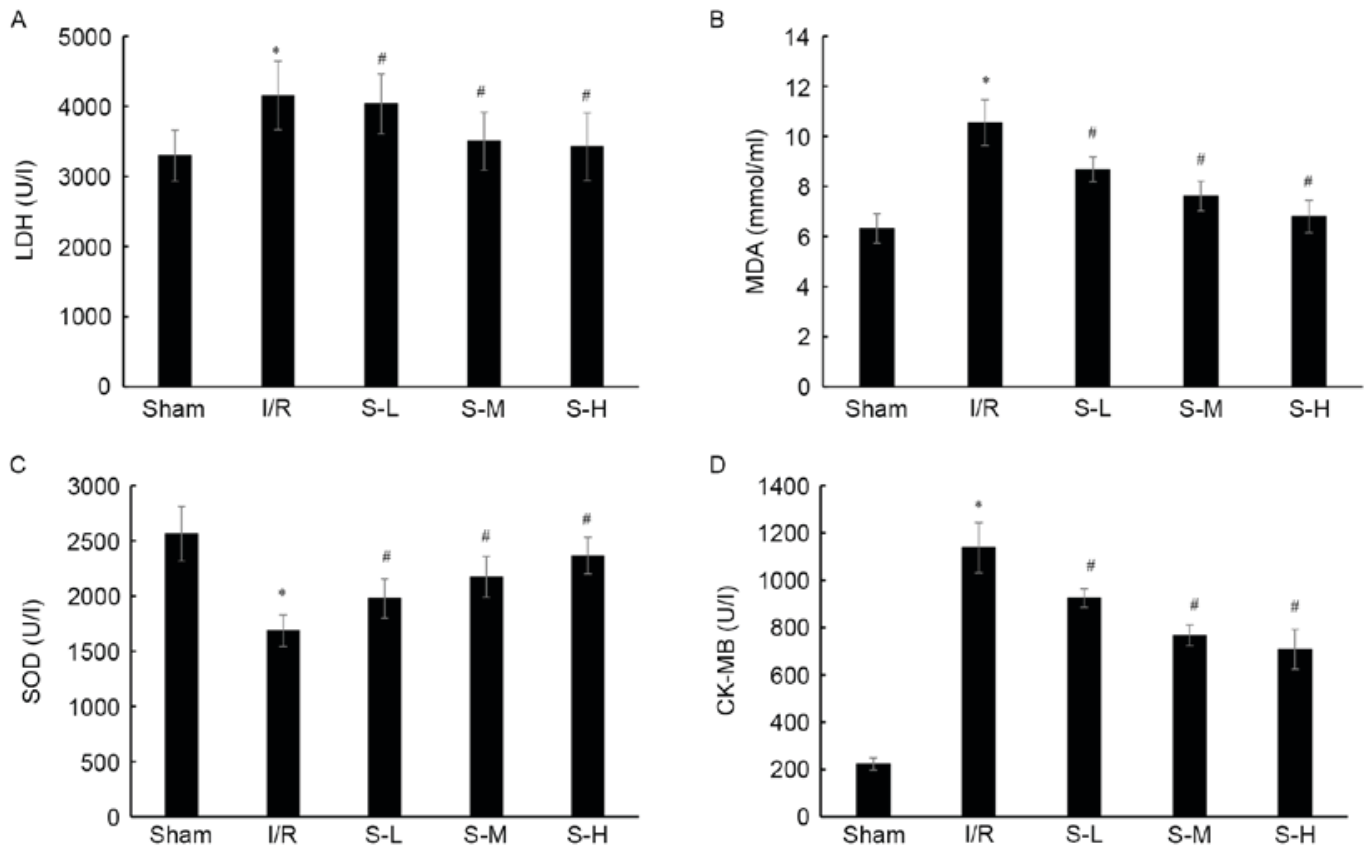

Figure 4. Effects of scoparone on (A) LDH, (B) MDA, (C) SOD and (D) CK levels in rats following I/R injury. With the exception of the sham group, the other groups underwent ischemia for $30 \mathrm{~min}$, followed by $120 \mathrm{~min}$ of reperfusion. Rats in the sham and I/R groups were intravenously injected with $2 \mathrm{ml} / \mathrm{kg}$ normal saline. Rats in the S-L, S-M and S-H groups were intravenously injected with 25,50 and $100 \mathrm{mg} / \mathrm{kg}$ scoparone respectively. Data are presented as the means \pm standard deviation ( $\mathrm{n}=24 /$ group). $\mathrm{P}<0.05$ vs. the sham group; $\mathrm{P}<0.05$ vs. the $\mathrm{I} / \mathrm{R}$ group. $\mathrm{CK}$, creatine kinase; I/R, ischemia-reperfusion; $\mathrm{LDH}$, lactate dehydrogenase; MDA, malondialdehyde; S-H, scoparone high-dose; S-L, scoparone low-dose; S-M, scoparone mid-dose; SOD, superoxide dismutase.

$100,500,1,000 \mathrm{mg} / \mathrm{ml}$, significantly and dose-dependently decreased caspase-3 and Cyt $\mathrm{C}$ expression following OGD/R injury of cardiac myocytes.

The effects of scoparone on caspase- 3 and Cyt $C$ expression in $\mathrm{I} / \mathrm{R}$ rats were detected by immunohistochemical staining. As shown in Fig. 9, I/R administration markedly increased caspase- 3 and Cyt $C$ expression compared with in the sham group; however, scoparone inhibited I/R-induced caspase- 3 and Cyt $\mathrm{C}$ expression in a dose-dependent manner. 

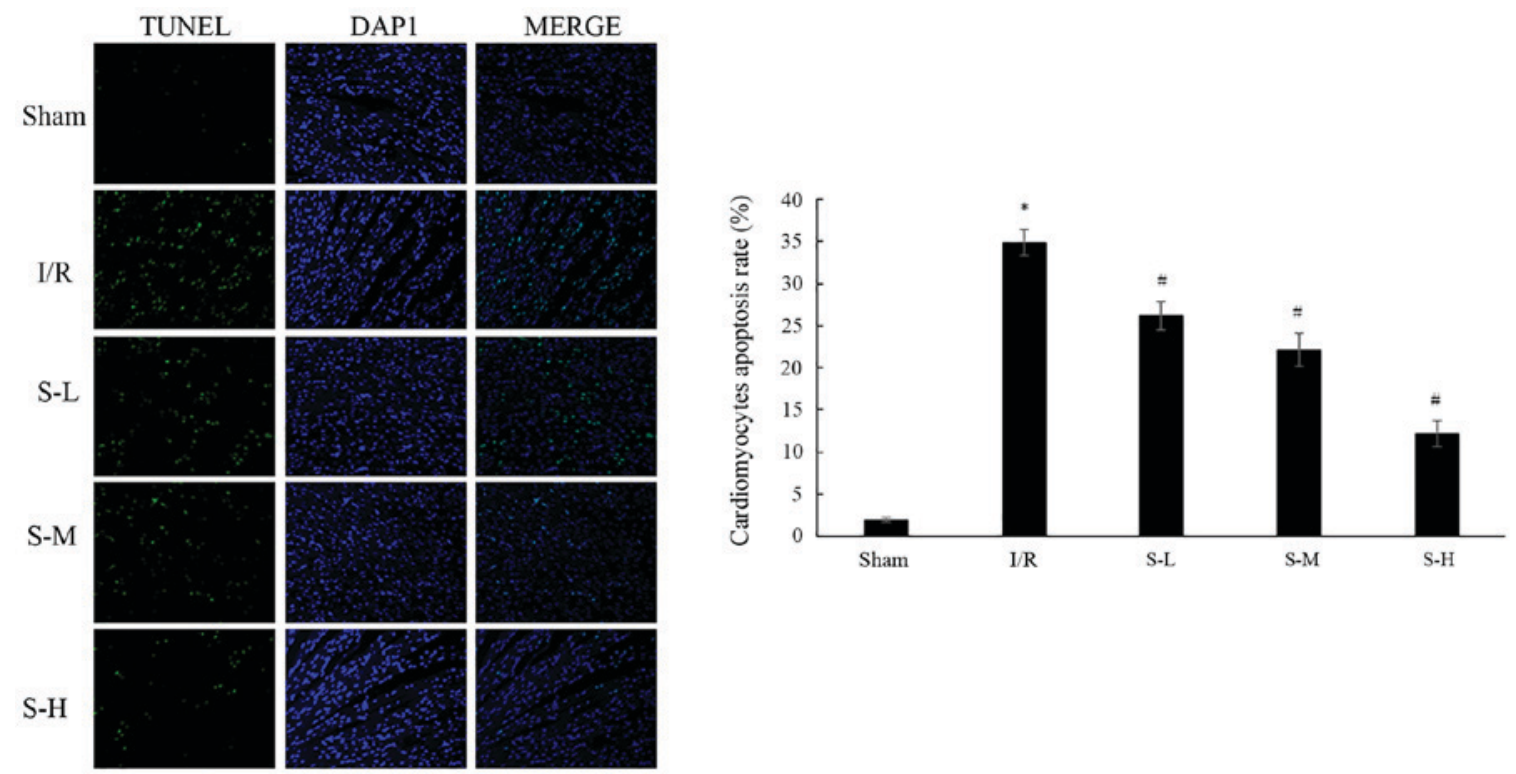

Figure 5. Effects of scoparone on cell apoptosis in rats following I/R injury. With the exception of the sham group, the other groups underwent ischemia for $30 \mathrm{~min}$, followed by $120 \mathrm{~min}$ of reperfusion. Rats in the sham and I/R groups were intravenously injected with $2 \mathrm{ml} / \mathrm{kg}$ normal saline. Rats in the S-L, S-M and $\mathrm{S}-\mathrm{H}$ groups were intravenously injected with 25,50 and $100 \mathrm{mg} / \mathrm{kg}$ scoparone respectively. Data are presented as the means \pm standard deviation (n=24/group). ${ }^{\text {"P }}<0.05$ vs. the sham group; ${ }^{*} \mathrm{P}<0.05$ vs. the I/R group. I/R, ischemia-reperfusion; $\mathrm{S}-\mathrm{H}$, scoparone high-dose; S-L, scoparone low-dose; S-M, scoparone mid-dose; TUNEL, terminal deoxynucleotidyl-transferase-mediated dUTP nick end labeling.

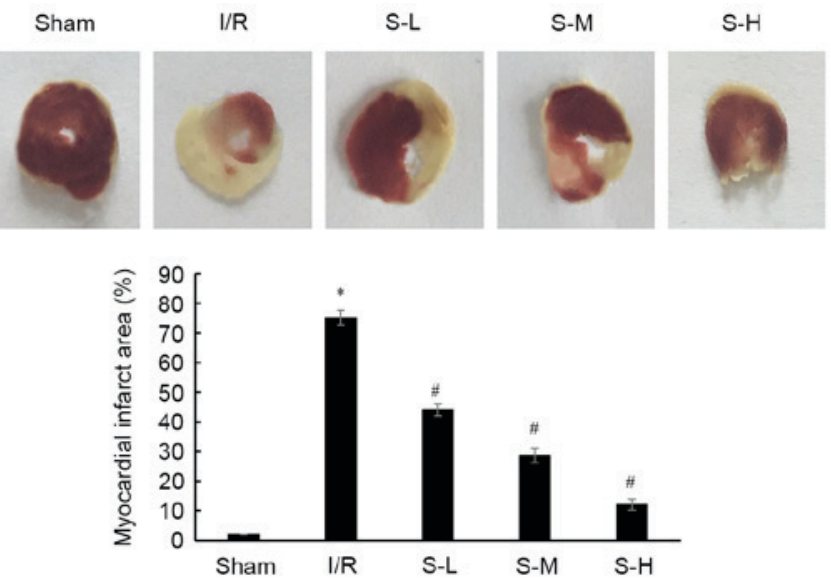

Figure 6. Effects of scoparone on myocardial infarct area in rats following I/R injury. With the exception of the sham group, the other groups underwent ischemia for $30 \mathrm{~min}$, followed by $120 \mathrm{~min}$ of reperfusion. Rats in the sham and I/R groups were intravenously injected with $2 \mathrm{ml} / \mathrm{kg}$ normal saline. Rats in the S-L, S-M and S-H groups were intravenously injected with 25,50 and $100 \mathrm{mg} / \mathrm{kg}$ scoparone respectively. Data are presented as the means \pm standard deviation ( $\mathrm{n}=24 /$ group). ${ }^{*} \mathrm{P}<0.05$ vs. the sham group; ${ }^{\#} \mathrm{P}<0.05$ vs. the $\mathrm{I} / \mathrm{R}$ group. I/R, ischemia-reperfusion; $\mathrm{S}-\mathrm{H}$, scoparone high-dose; S-L, scoparone low-dose; S-M, scoparone mid-dose.

Effects of scoparone on Bcl-2 and Bax expression. As shown in Figs. 8 and 9, I/R injury induced an increase in Bax expression and a decrease in Bcl-2 expression in a cell model of OGD/R model and a rat model of I/R. Conversely, treatment with scoparone attenuated these alterations in a dose-dependent manner.

\section{Discussion}

Myocardial ischemia can cause tissue damage and cell death over a certain period of time; therefore, rapid restoration of blood

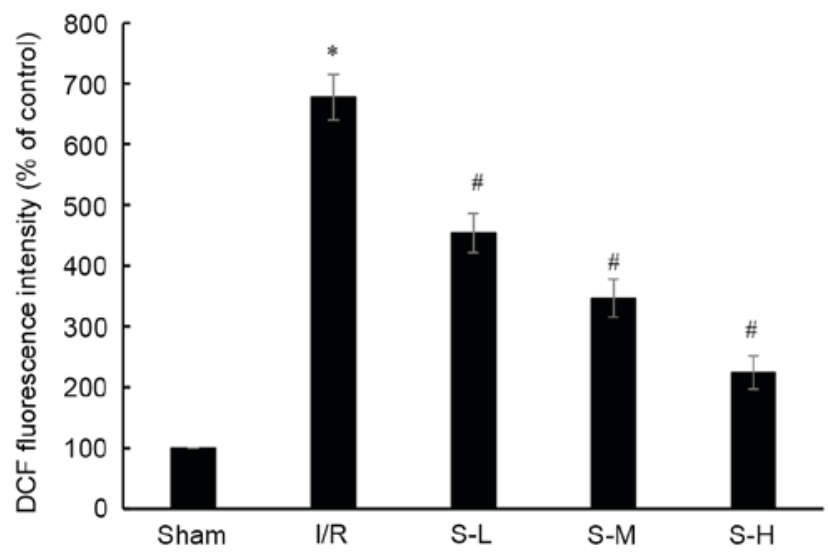

Figure 7. Effects of scoparone on ROS concentration in rats following I/R injury. DCF fluorescence intensity of the sham group cells was set at $100 \%$ for comparison with the fluorescence intensity of the other groups. With the exception of the sham group, the other groups underwent ischemia for $30 \mathrm{~min}$, followed by $120 \mathrm{~min}$ of reperfusion. Rats in the sham and I/R groups were intravenously injected with $2 \mathrm{ml} / \mathrm{kg}$ normal saline. Rats in the $\mathrm{S}$-L, S-M and S-H groups were intravenously injected with 25,50 and $100 \mathrm{mg} / \mathrm{kg}$ scoparone respectively. Data are presented as the means \pm standard deviation ( $\mathrm{n}=24$ /group). ${ }^{*} \mathrm{P}<0.05$ vs. the sham group; ${ }^{\text {}} \mathrm{P}<0.05$ vs. the I/R group. I/R, ischemia-reperfusion; S-H, scoparone high-dose; S-L, scoparone low-dose; S-M, scoparone mid-dose.

perfusion is required for cardiac myocyte survival. I/R injury in myocardial tissue is mediated by calcium overload, ROS generation, cell apoptosis and disordered energy metabolism, which may eventually lead to organ damage and myocardial metabolic disorder. LDH is present in the cytoplasm of all tissues. When cell apoptosis or necrosis occurs, the membrane structure is destroyed, thus leading to the release of LDH from the cytoplasm to outside of the cell. Therefore, detecting LDH levels may indirectly reflect the extent of the damage to the cell membrane (18). CK is a cardiac-specific marker of acute 

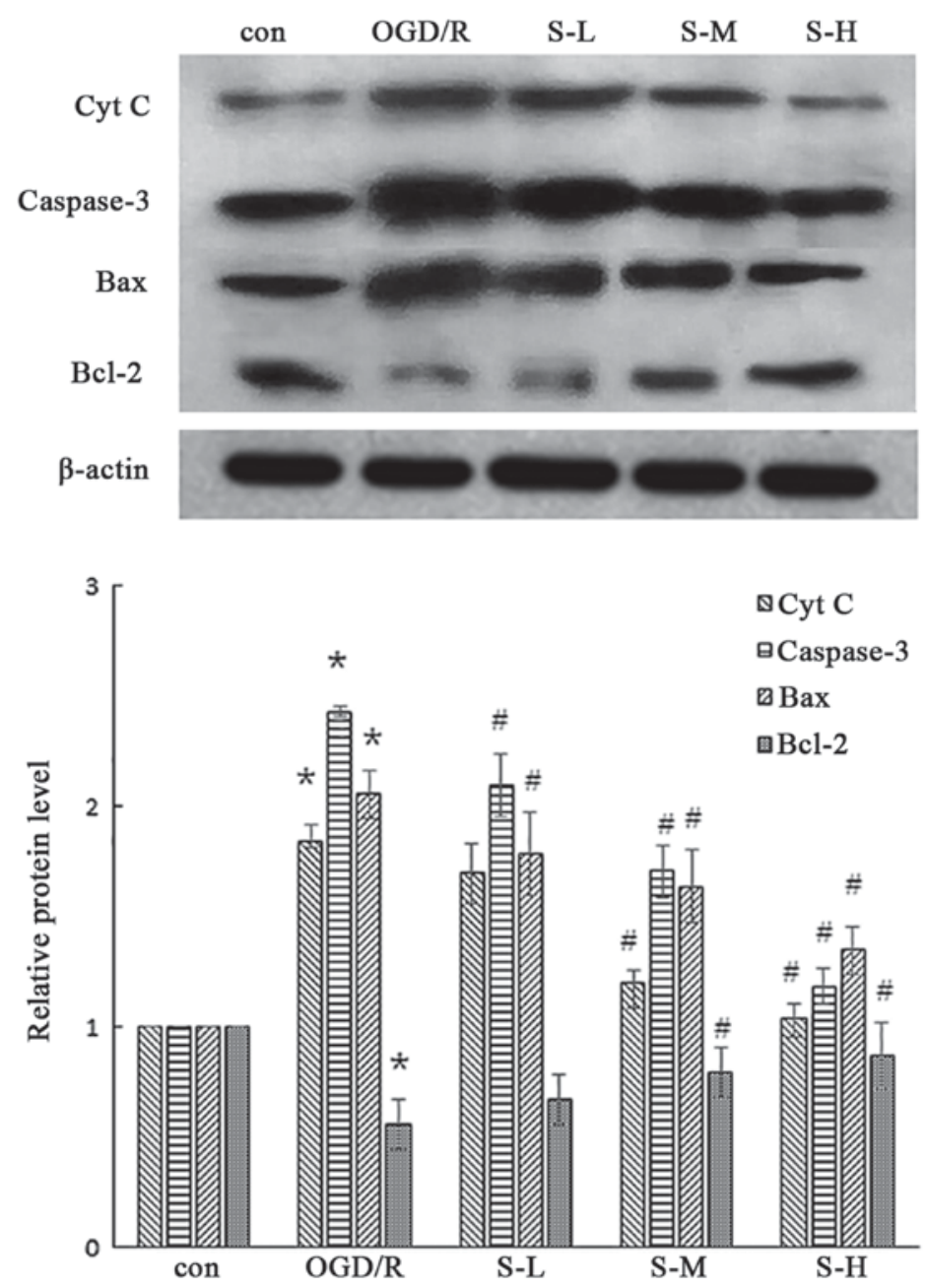

Figure 8. Effects of scoparone on the expression levels of caspase-3, Cyt C, Bcl-2 and Bax in cardiac myocytes following OGD/R injury. "P<0.05 vs. the Con group; ${ }^{\# \mathrm{P}}<0.05$ vs. the $\mathrm{OGD} / \mathrm{R}$ group. Data are presented as the means \pm standard deviation $(\mathrm{n}=3)$. Bax, Bcl-2-associated $\mathrm{X}$ protein; Bcl-2, B-cell lymphoma 2; Con, control; Cyt C, cytochrome $c$; OGD/R, oxygen-glucose deprivation/reoxygenation; S-H, scoparone high-dose; S-L, scoparone low-dose; S-M, scoparone mid-dose.

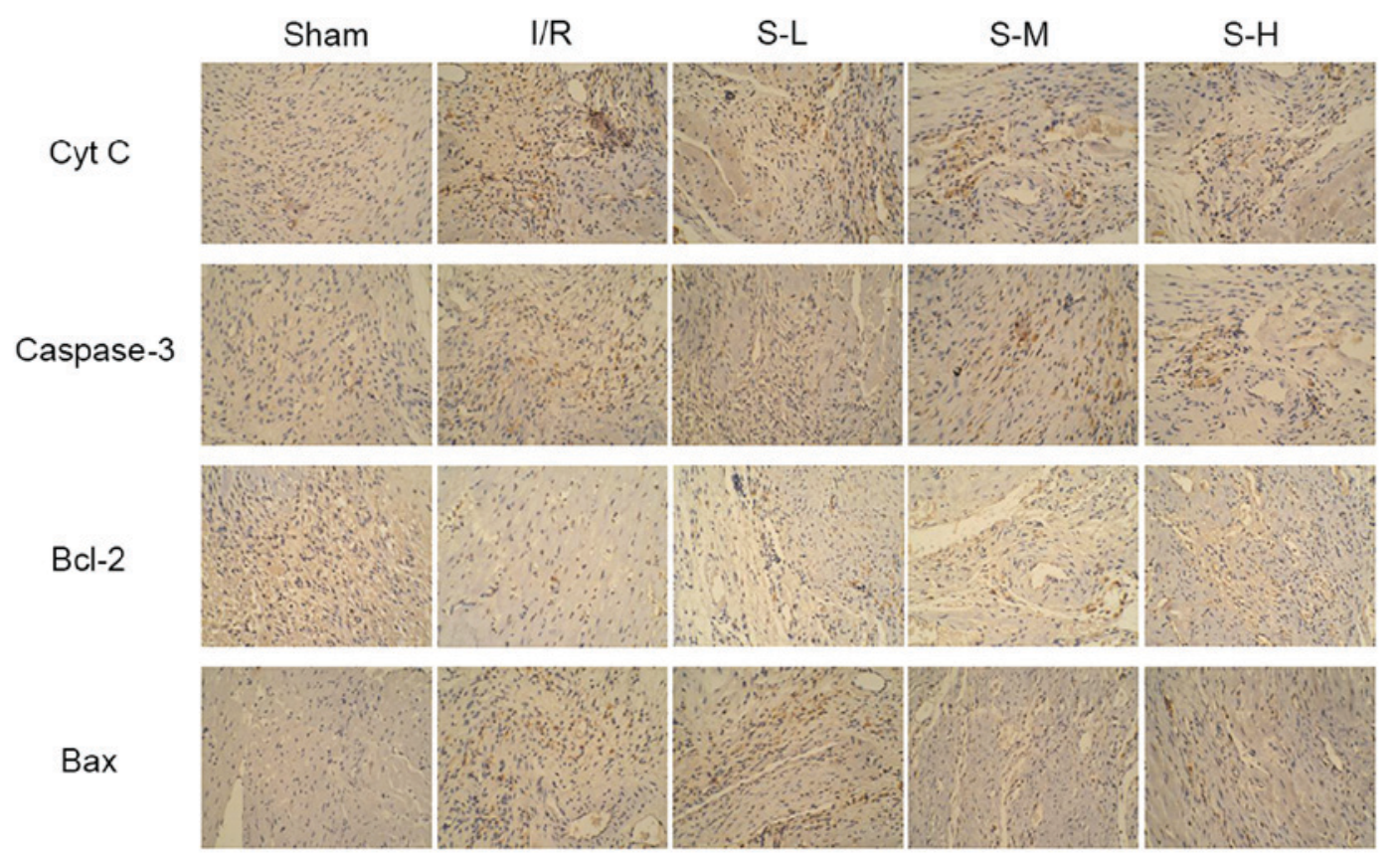

Figure 9. Effects of scoparone on the expression of caspase-3, Cyt C, Bcl-2 and Bax in rats following I/R injury (x40). Bax, Bcl-2-associated X protein; Bcl-2, B-cell lymphoma 2; Cyt C, cytochrome $c$; I/R, ischemia-reperfusion; S-H, scoparone high-dose; S-L, scoparone low-dose; S-M, scoparone mid-dose. 
myocardial infarction and an indicator for myocardial tissue injury. An increase in serum levels of CK indicates that the myocardial cell biological membrane is damaged. Myocardial hypoxia produces a large amount of ROS, which oxidize unsaturated fatty acids, leading to damaged cell membrane structure and sarcoplasmic reticulum calcium pump function, thus inducing extracellular $\mathrm{Ca}^{2+}$ internal flow and calcium overload. Calcium overload accelerates ROS generation and causes myocardial cell damage (19). ROS also damage the mitochondrial membrane system, oxidize $\mathrm{Cyt} \mathrm{C}$ and reduce the activity of ATP synthetase, thus resulting in mitochondrial dysfunction, which can lead to cell apoptosis (20). MDA is formed by lipid peroxidation, and is often used to quantify the extent of lipid peroxidation and reflects the damage caused by $\operatorname{ROS}(14,21)$. SOD is an important antioxidant, which has exhibits ROS scavenging properties. During tissue ischemia, SOD is consumed in large quantities, and SOD synthesis of SOD is suppressed, resulting in a decrease in SOD levels. The serum levels of SOD are able to reflect the ability to clear ROS.

It has previously been reported that $\mathrm{Bcl}-2$ and $\mathrm{Bax}$ are involved in the process of myocardial cell apoptosis (22), and the ratio of Bc1-2 to Bax may be a critical factor for apoptosis (23). The caspase cascade also serves a key role in apoptosis (24); caspase-3 typically functions downstream of other caspases and directly activates enzymes that are responsible for DNA fragmentation in the intrinsic apoptosis pathway (25).

Scoparone is a major component of the shoot of Artemisiae Scopariae Herba. In the present study, scoparone was revealed to exert a protective effect on I/R-induced myocardial injury.

The results of the present study demonstrated that I/R leads to an increase in LDH levels, MDA and CK content, ROS generation, cell apoptosis and myocardial IA, these alterations are accompanied by reductions in cell viability and SOD activity. However, pretreatment with scoparone prior to I/R injury, significantly decreased LDH levels, MDA production, CK levels and ROS generation, and increased SOD activity. These results indicated that scoparone may reduce ROS-induced cell lipid peroxidation. In addition, scoparone was able to increase cell viability, and decrease cell apoptosis and myocardial IA in a dose-dependent manner following I/R. Furthermore, there was a marked reduction in the expression levels of Bax, caspase-3 and Cyt C, alongside a significant increase in the expression levels of Bcl-2 in scoparone-treated groups compared with in the I/R group. Myocardial cell apoptosis is induced by various factors and involves two main signaling pathways: The death receptor pathway and the mitochondrial signaling pathway, during which the mitochondria receive various apoptosis-stimulating signals. Apoptosis-stimulating signal, including ROS, attack the mitochondrial membrane, which is rich in polyunsaturated fatty acids, thus causing mitochondrial swelling, decreases in membrane fluidity, opening of the mitochondrial membrane permeability transition pore and Cyt $\mathrm{C}$ release. Eventually, the caspase protease cascade is activated; caspase-9 is activated first, which further activates the downstream effector molecule caspase-3, thus leading to cell apoptosis. The Bcl-2 family serves an important role in the mitochondrial-dependent apoptotic pathway, and includes proapoptotic and anti-apoptotic proteins. The $\mathrm{Bcl}-2$ protein is distributed in the outer mitochondrial membrane; Bcl-2 has an anti-apoptotic role via inhibition of Cyt $\mathrm{C}$ release, thus suppressing activation of the downstream caspase cascade. Bax is a proapoptotic protein that belongs to the Bcl-2 family; Bax is mainly located in the cytoplasm, and it can transfer to the outer mitochondrial membrane in response to stimulation by apoptotic signals. Bax can induce cell apoptosis by increasing permeability of the mitochondrial outer membrane to promote the release of Cyt C (26). The results of the present study suggested that scoparone inhibited cell apoptosis by influencing the aforementioned pathway.

In conclusion, scoparone may significantly reduce the formation of MDA, enhance SOD activity, decrease LDH and CK levels, and attenuate the myocardial IA. In addition, scoparone is able to inhibit cell apoptosis, upregulate Bcl-2 expression, and downregulate Bax, caspase- 3 and $\mathrm{Cyt} C$ protein expression. These findings suggested that scoparone can scavenge ROS, reduce oxidative stress, protect mitochondria, improve myocardial dysfunction and inhibit cell apoptosis induced by $\mathrm{I} / \mathrm{R}$ via the mitochondrial pathway.

\section{Acknowledgements}

Not applicable.

\section{Funding}

The present study was supported by grants from the Key Research Program of Medical Science in Hebei Province (grant no. ZD 20140004).

\section{Availability of data and materials}

The datasets generated and/or analyzed during the current study are not publicly available due to further research but are available from the corresponding author on reasonable request.

\section{Authors' contributions}

$\mathrm{CW}$ and $\mathrm{XG}$ participated in the research design. $\mathrm{CW}, \mathrm{YW}$ and $\mathrm{JM}$ conducted experiments. $\mathrm{CW}$ and $\mathrm{YW}$ performed data analysis. CW was a major contributor in writing the manuscript. All authors read and approved the final manuscript.

\section{Ethics approval and consent to participate}

The present study was approved by the Ethics Committee of Hebei Medical University (Shijiazhuang, China).

\section{Consent for publication}

Not applicable.

\section{Conflicts of interest}

The authors declare that they have no competing interests.

\section{References}

1. Okuno I, Uchida K, Nakamura M and Sakurawi K: Studies on choleretic constituents in Artemisia capillaris THUNB. Chem Pharm Bull (Tokyo) 36: 769-775, 1988. 
2. Yoon M and Kim MY: The anti-angiogenic herbal composition Ob-X from Morus alba, Melissa officinalis and Artemisia capillaris regulates obesity in genetically obese ob/ob mice. Pham Biol 49: 614-619, 2011.

3. Ulicná O, Greksák M, Vancová O, Zlatos L, Galbavý S, Bozek P and Nakano M: Hepatoprotective effect of rooibos tea (Aspalathus linearis) on CCl4-induced liver damage in rats. Physiol Res 52: 461-466, 2003

4. Lee HI, Seo KO, Yun KW, Kim MJ and Lee MK: Comparative study of the hepatoprotective efficacy of Artemisia iwayomogi and Artemisia capillaris on ethanol-administered mice. J Food Sci 76: T207-T211, 2011.

5. Jin X, Uchiyama M, Zhang Q, Watanabe $T$ and Niimi M: Artemisiae capillaris herba induces prolonged survival of fully cardiac allografts and generates regulatory cells in mice. Transplant Proc 44: 1073-1075, 2012.

6. Kwon OS, Choi JS, Islam MN, Kim YS and Kim HP: Inhibition of 5-lipoxygenase and skin inflammation by the aerial parts of Artemisia capillaris and its constituents. Arch Pharm Res 34: 1561-1569, 2011.

7. Habib $M$ and Waheed I: Evaluation of anti-nociceptive, anti-inflammatory and antipyretic activities of Artemisia scoparia hydromethanolic extract. J Ethnopharmacol 145: 18-24, 2013.

8. Jang SI, Kim YJ, Kim HJ, Lee JC, Kim HY, Kim YC, Yun YG $\mathrm{Yu} \mathrm{HH}$ and You YO: Scoparone inhibits PMA-induced IL-8 and MCP-1 production through suppression of NFkappaB activation in U937 cells. Life Sci 78: 2937-2943, 2006.

9. Jang SI, Kim YJ, Lee WY, Kwak KC, Baek SH, Kwak GB Yun YG, Kwon TO, Chung HT and Chai KY: Scoparone from Artemisia capillaris inhibits the release of inflammatory mediators in RAW 264.7 cells upon stimulation cells by interferon-gamma Plus LPS. Arch Pharm Res 28: 203-208, 2005.

10. Kim JK, Kim JY, Kim HJ, Park KG, Harris RA, Cho WJ, Lee JT and Lee IK: Scoparone exerts anti-tumor activity against DU145 prostate cancer cells via inhibition of STAT3 activity. PLoS One 8: e80391, 2013.

11. Huang W, Zhang J and Moore DD: A traditional herbal medicine enhances bilirubin clearance by activating the nuclear receptor CAR. J Clin Invest 113: 137-143, 2004.

12. Huang HC, Weng YI, Lee CR, Jan TR, Chen YL and Lee YT: Protection by scoparone against the alterations of plasma lipoproteins, vascular morphology and vascular reactivity in hyperlipidaemic diabetic rabbit. Br J Pharmacol 110: 1508-1514, 1993.

13. Morisco C, Zebrowski D, Condorelli G, Tsichlis P, Vatner SF and Sadoshima J: The akt-glycogen synthase kinase 3beta pathway regulates transcription of atrial natriuretic factor induced by beta-adrenergic receptor stimulation in cardiac myocytes. J Biol Chem 275: 14466-14475, 2000.
14. Wu L, Qiao $\mathrm{H}, \mathrm{Li} \mathrm{Y}$ and Li L: Protective roles of puerarin and Danshensu on acute ischemic myocardial injury in rats. Phytomedicine 14: 652-658, 2007.

15. Yang J, Zhang XD, Yang J, Ding JW, Liu ZQ, Li SG and Yang R: The cardioprotective effect of fluvastatin on ischemic injury via down-regulation of toll-like receptor 4. Mol Biol Rep 38: 3037-3044, 2011

16. Zhao ZY, Luan P, Huang SX, Xiao SH, Zhao J, Zhang B, $\mathrm{Gu} \mathrm{BB}, \mathrm{Pi} \mathrm{RB}$ and Liu J: Edaravone protects HT22 neurons from $\mathrm{H}_{2} \mathrm{O}_{2}$-induced apoptosis by inhibiting the MAPK signaling pathway. CNS Neurosci Ther 19: 163-169, 2013.

17. Longa EZ, Weinstein PR, Carlson S and Cummins R: Reversible middle cerebral artery occlusion without craniectomy in rats. Stroke 20: 84-91, 1989.

18. Zhang L, Ma J and Liu H: Protective effect of ischemic postconditioning against ischemia reperfusion-induced myocardium oxidative injury in IR rats. Molecules 17: 3805-3817, 2012.

19. Goldhaber JI and Qayyum MS: Oxygen free radicals and excitation-contraction coupling. Antioxid Redox Signal 2: 55-64, 2000.

20. Paredies G, Pelrosillo G, Pistolese M, Di Venosa N, Federici A and Ruggiero FM: Decrease in mitoehondrial complex 1 activity in ischemic/reperfused rat heart: In-volvement of reactive oxygen species and eardiolipin. Cire Res 94: 53-59, 2004.

21. Zheng W, Huang LZ, Zhao L, Wang B, Xu HB, Wang GY, Wang ZL and Zhou H: Superoxide dismutase activity and malondialdehyde level in plasma and morphological evaluation of acute severe hemorrhagic shock in rats. Am J Emerg Med 26: 54-58, 2008.

22. Kluck RM, Bossy-Wetzel E, Green DR and Newmeyer DD: The release of cytochrome $\mathrm{c}$ from mitochondria: A primary site for Bcl-2 regulation of apoptosis. Science 275: 1132-1136, 1997.

23. Tamm I, Schriever F and Dörken B: Apoptosis: Implications of basic research for clinical oncology. Lancet Oncol 2: 33-42, 2001

24. Lakhani SA, Masud A, Kuida K, Porter GA Jr, Booth CJ, Mehal WZ, Inayat I and Flavell RA: Caspases 3 and 7: Key mediators of mitochondrial events of apoptosis. Science 311: 847-851, 2006

25. Wu Q, Li H, Wu Y, Shen W, Zeng L, Cheng H and He L: Protective effects of muscone on ischemia-reperfusion injury in cardiac myocytes. J Ethnopharmacol 138: 34-39, 2011.

26. Song JQ and Liu YX: Effect of ramipril on ischemia -reperfusion induced apoptosis of cardiomyocyte and expression of apoptosis related genes. Chin Pharm Acol Bull 22: 625-628, 2006. 